\title{
MAY 111960
}

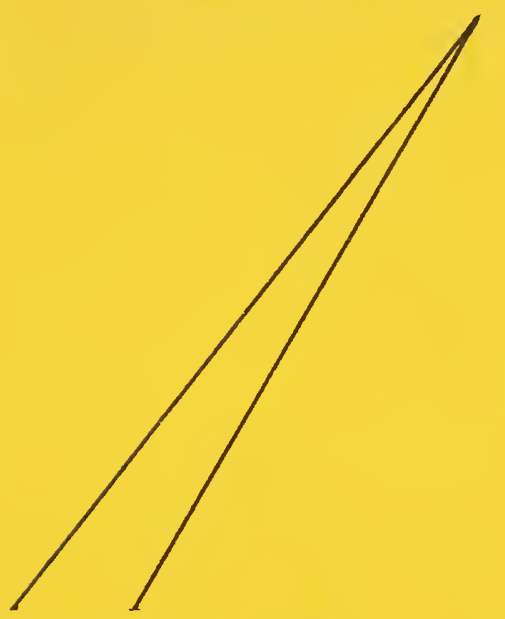

Calibration of Line Standards of

Length and Measuring Tapes at

The National Bureau of Standards

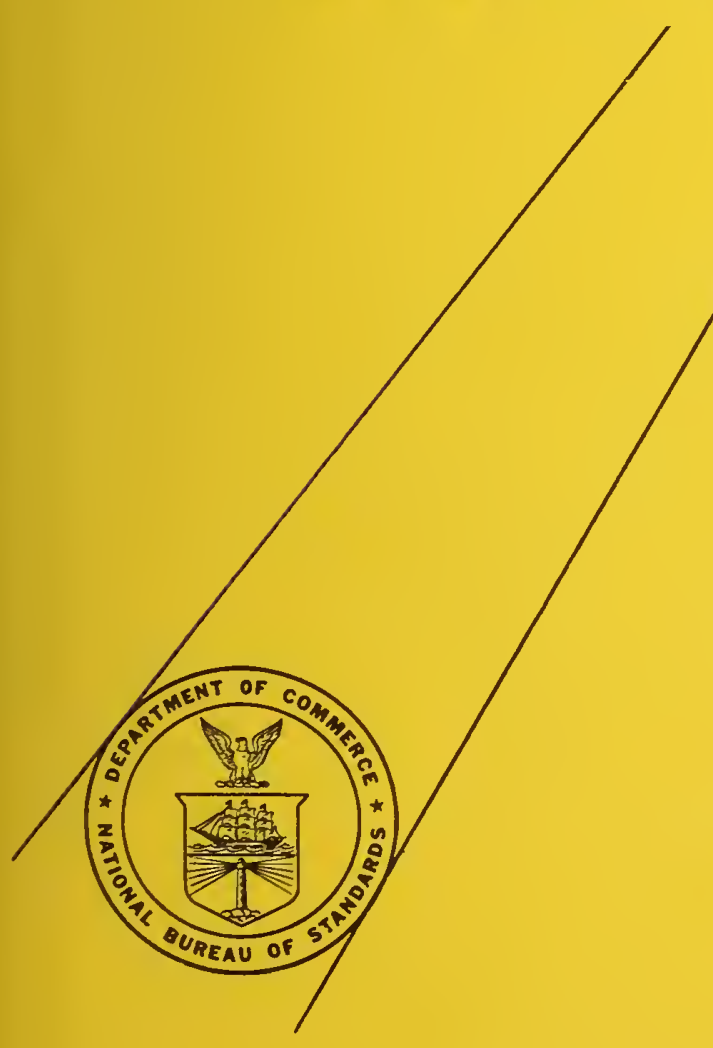

\author{
U.S. DEPARTMENT OF COMMERCE \\ NATIONAL BUREAU OF STANDARDS
}




\section{THE NATIONAL BUREAU OF STANDARDS}

\section{Functions and Activities}

The functions of the National Bureau of Standards are set forth in the Act of Congress, March 3, 1901, as amended by Congress in Public Law 619, 1950. These include the development and maintenance of the national standards of measurement and the provision of means and methods for making measurements consistent with these standards; the determination of physical constants and properties of materials; the development of methods and instruments for testing materials, devices, and structures; advisory services to government agencies on scientific and technical problems; invention and development of devices to serve special needs of the Government; and the development of standard practices, codes, and specifications. The work includes basic and applied research, development, engineering, instrumentation, testing, evaluation, calibration services, and various consultation and information services. Research projects are also performed for other government agencies when the work relates to and supplements the basic program of the Bureau or when the Bureau's unique competence is required. The scope of activities is suggested by the listing of divisions and sections on the inside of the back cover.

\section{Publications}

The results of the Bureau's work take the form of either actual equipment and devices or published papers. These papers appear either in the Bureau's own series of publications or in the journals of professional and scientific societies. The Bureau itself publishes three periodicals available from the Government Printing Office: The Journal of Research, published in four separate sections, presents complete scientific and technical papers; the Technical News Bulletin presents summary and preliminary reports on work in progress; and Basic Radio Propagation Predictions provides data for determining the best frequencies to use for radio communications throughout the world. There are also five series of nonperiodical publications: Monographs, Applied Mathematics Series, Handbooks, Miscellaneous Publications, and Technical Notes.

Information on the Bureau's publications can be found in NBS Circular 460, Publications of the National Bureau of Standards (\$1.25) and its Supplement (\$1.50), available from the Superintendent of Documents, Government Printing Office, Washington 25, D.C. 


\section{Calibration of Line Standards of Length and Measuring Tapes at The National Bureau of Standards}

Lewis $\mathrm{V}$. Judson

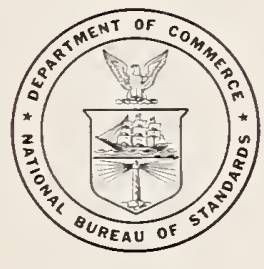

National Bureau of Standards Monograph 15

Issued May 20, 1960

Supersedes Circular 572

For sale by the Superintendent of Documents, U.S. Government Printing Office, Washington 25, D.C. - Price 15 cents 



\section{Contents}

1. Introduction

2. Line standards of length at NBS

3. Facilities for calibrating line standards of length

4. Facilities for calibrating measuring tapes

4.1. Steel-tape bench

4.2. Geodetic tape comparator

5. Calibration of line standards of length

5.1. Reference standards....... 4

5.2. Working standards $\ldots \ldots$

5.3. Commercial standards $\ldots \ldots \ldots$

6. Calibration of measuring tapes._. 5

6.1. Specification for standard steel tapes

6.2. Certification of tapes

6.3. Standard procedures in steel-tape calibrations

6.4. Corrections applicable to steel tapes

6.5. Base-line tapes

7. Certificates and reports

8. Cooperation with officials and others

9. General instructions to applicants for calibrations_._. 8

9.1. Apparatus accepted for calibration

9.2. Application for calibration

9.3. Nature of calibration 8

9.4. Special calibrations

9.5. Condition of apparatus _. 8

9.6. Identification of apparatus.

9.7. Shipping instructions

9.8. Schedule of test fees

9.9. Address

10. Appendix-Use of steel tapes. 


\title{
Calibration of Line Standards of Length and Measuring Tapes at the National Bureau of Standards
}

\begin{abstract}
Lewis V. Judson
The methods used at the National Bureau of Standards in calibrating line standards of length and measuring tapes submitted for standardization are outlined. The equipment used is described briefly. There is a discussion of some considerations that should be given as to whether or not a standard should be submitted to the Bureau. Instructions are given for submitting items to the Bureau for calibration. The appendix contains useful information on the use of steel tapes.
\end{abstract}

\section{Introduction}

The Bureau receives many requests from scientists, industry, and governmental agencies to calibrate line standards of length and measuring tapes. This Monograph is issued as a guide for anyone contemplating the submission of such items to the Bureau for standardization. It replaces Circular 332, Testing of line standards of length; Circular 328, Testing of measuring tapes at the National Bureau of Standards; and Circular 572. Calibration of line standards of length and measuring tapes at the National Bureau of Standards.

\section{Line Standards of Length at NBS}

The primary standard of length in the United States is the National Prototype Meter 27 (fig. 1), which is identical in form and material with the International Prototype Meter deposited at the International Bureau of Weights and Measures at Sèrres, near Paris, and also with the other national prototype meters distributed in 1889 in accordance with the treaty known as the Convention of the Meter, dated May 20, 1875. Except for expressing data in feet derived from and published as a result of geodetic survers within the United States, for which the relation 1 foot $=1200 / 3937$ meter $^{\circ}$ col tinues to be used, the rard in the United States is clefined in terms of the meter by the relation

$$
1 \text { yard }=0.9144 \text { meter. }
$$

At the Bureau there are secondary and laboratory length standards of various materials, sizes, and degrees of precision. 'Their lengths are known in terms of the prototype meter. These secondary and laboratory standards are used in the calibration work done by the Bureau.

Proposals have been made to adopt, as the definition of the meter, a specified number of wavelengths of a suitable isotope of an element such as mercury (for example, the 5461-A wavelength of mercury 198). Interferometric calibrations of end standards of length have been made for many years. Such calibrations of line standards of length have been made in Germany, and the method is being followed with considerable interest at the Bureau.

\section{Facilities for Calibrating Line Standards of Length}

For the calibration of line standards of length the most precise measurements now being made at the Bureau are on its 1-m longitudinal comparator (fig. 2). This has been briefly described by Page. ${ }^{1}$ It is especially suited for the calibration of the subintervals of a bar, using any one of the several methods that have been developed. Although this comparator is nominally a $1-\mathrm{m}$ comparator, it is readily adaptable for standardizing 48-in. bars, and can be used for calibrating even longer bars.

For comparing two bars with an accuracy not better than 1 micron $(0.001 \mathrm{~mm}$ or $0.00004 \mathrm{in}$.) a simple transverse comparator with no thermal insulation is commonly used. In this instrument the bars are mounted parallel to each other, and the carriage supporting the two bars moves back

1 B. L. Page, Calibration of meter line standards of length at the National Bureau of Standards, J. Research NBS 54, 1 (1955) RP2559.

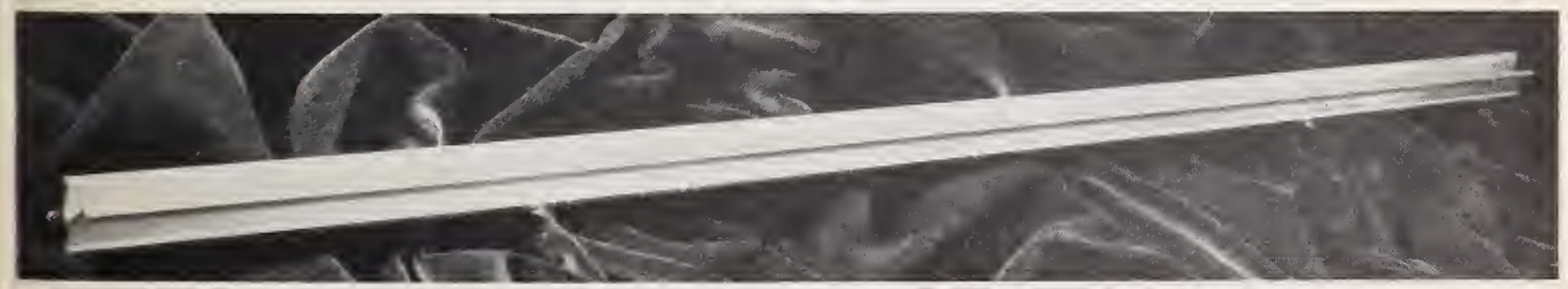

Figure 1. U. S. National Prototype Meter 27. 


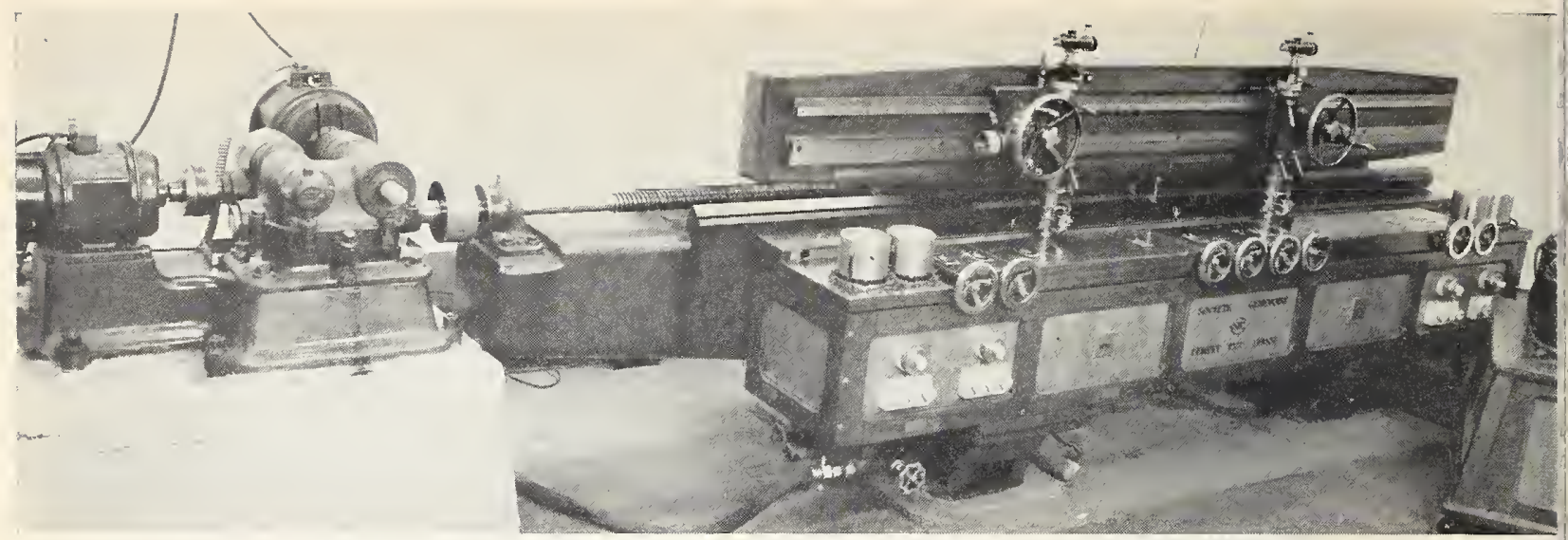

Figure 2. Longitudinal comparator of the National Bureau of Standards.

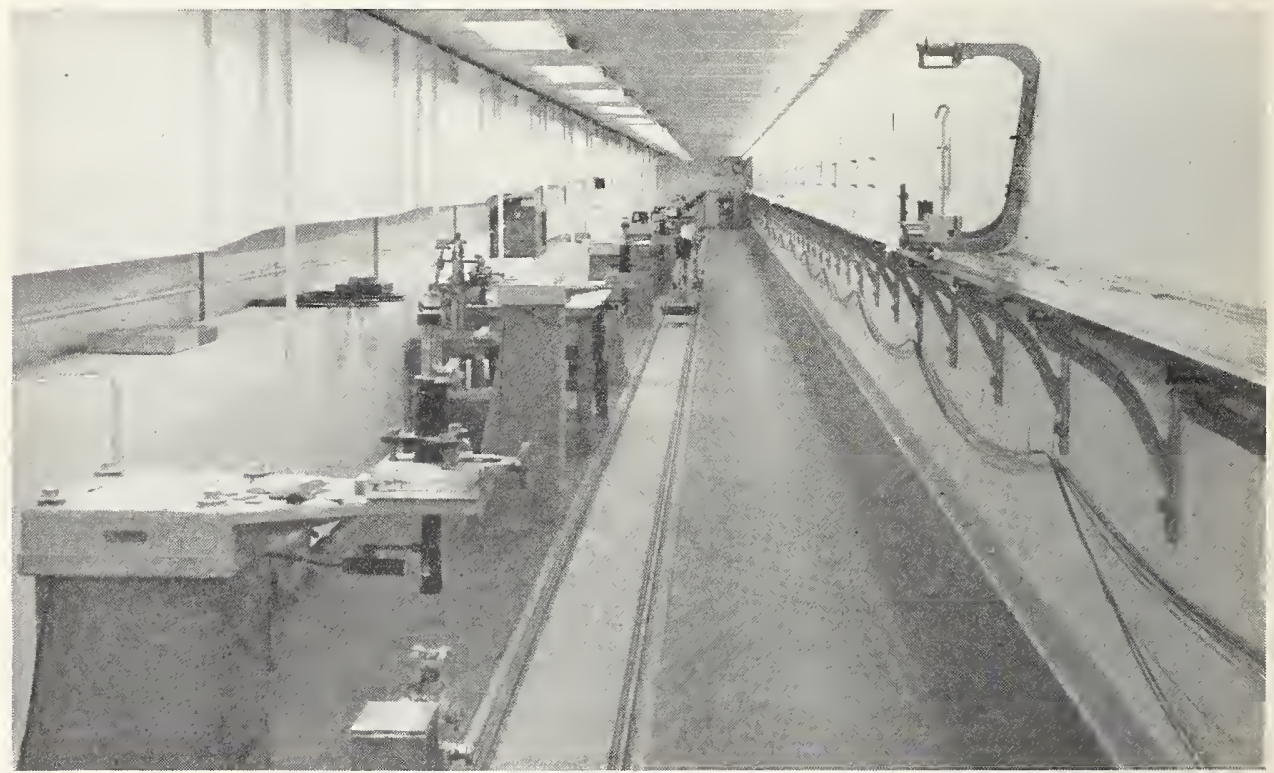

FIGURE 3. NBS tape calibration laboratory.

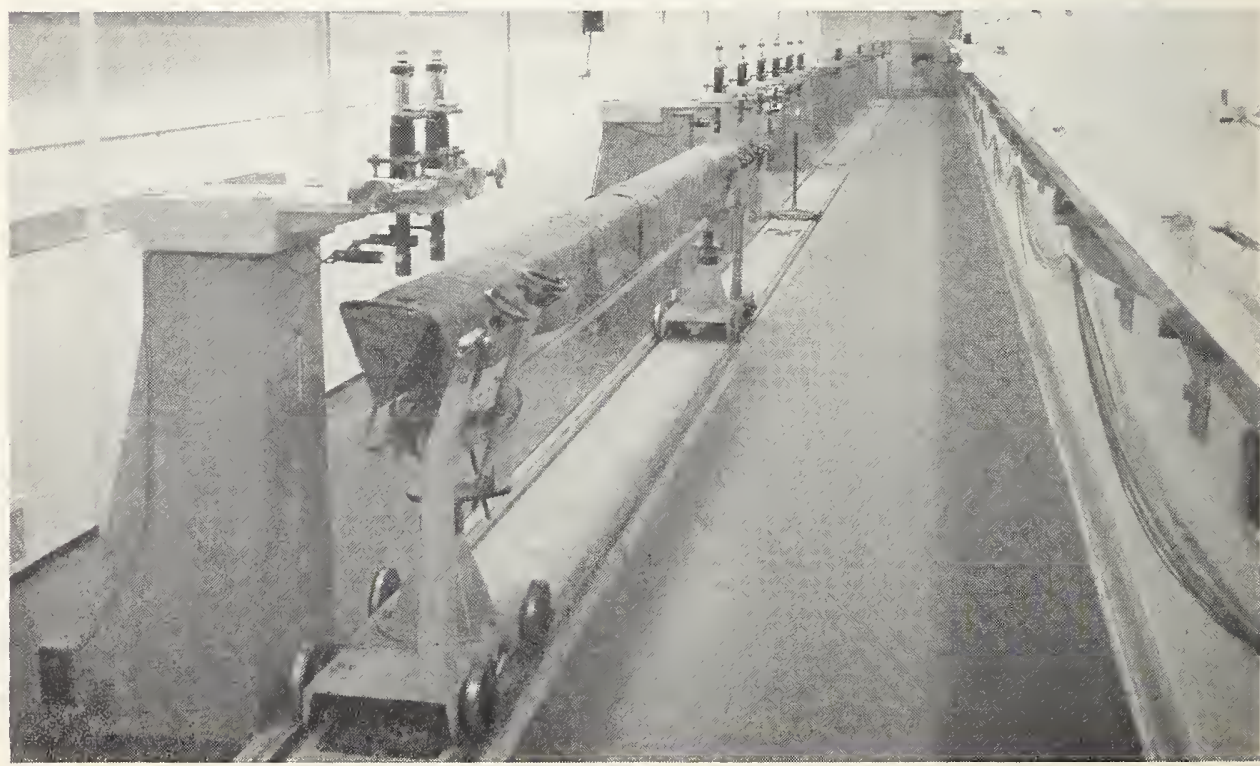

FIGURE 4. NBS tape calibration laboratory, showing some details of the geodetic comparotor. 
and forth in a direction perpendicular to a line parallel to the axis of each of the two bars. The micrometer microscopes are not inoved during a comparison with this transverse comparator.

Short bars and small scales are often more conreniently calibrated by means of a linear dividing engine haring two microscopes conveniently mounted so that they can be focused on the bars mounted on the longitudinally moving carriage. The instrument is then, in effect, a longitudinal comparator.

Micrometer microscopes having a pair of parallel "cross hairs" moring in the focus of a positire-type ocular are probably the most important parts of any instrument for comparing line standards of length. The movement of the cross wires is measured by a precision screw and a graduated drum. In the comparators in the length section at the Bureau the axes of the microscopes are rertical.

\section{Facilities for Calibrating Measuring Tapes}

At the Bureau there is a temperature-controlled laboratory a bout $212 \mathrm{ft}$ long (fig. 3). Two distinct installations have been made in this laboratory. One is a $200-\mathrm{ft}$ steel bench for calibrating steel tapes used in general surveying and engineering practice, as shown at the right in figure 3 . The other is a geodetic comparator designed especially for calibrating the $50-\mathrm{m}$ invar base-line tapes, such as are used by the U. S. Coast and Geodetic Survey. Its use is not limited, however, to a $50-\mathrm{m}$ length. It is shown at the left in figure 3.

\subsection{Steel-Tape Bench}

The steel-tape bench has an over-all length of $200 \mathrm{ft} 1 \mathrm{in}$., a width of $2 \frac{1}{2} \mathrm{in}$., and a thickness of ${ }_{3 / 4}^{3 / n}$., and is constructed of stainless-steel bars approximately $12 \mathrm{ft}$ long, with individually lapped and fitted ends. Stainless-steel conical dowel pins haring threaded lower ends for locking nuts securely hold adjoining bars in the correct position. The supports for the bench are attached firmly to the wall, but can be adjusted whenever necessary. The bench is graduated at intervals ordinarily required for testing tapes graduated in the metric or in the United States customary system. The equipment is furnished with the necessary supports for the tape when it is to be supported at specified points, with apparatus for applying the tension, thermometers for observing the temperature, and the necessary clamps and other auxiliary equipment.

Comparisons of a tape with the bench standard are ordinarily marle with a low-power microscope and a precision steel scale graduated either to $1 / 100$ in. or to $1 / 5 \mathrm{~mm}$. Then unusually high accuracy is required and the character of the graduation lines warrants, comparisons with the bench can be made with a micrometer microscope.

\subsection{Geodetic Tape Comparator}

A 5-m bar, packed in melting ice when measurements are being taken, is the working standard used as the basis of measurements in the geodetic tape comparator. Piers bearing microscopes are spaced $5 \mathrm{~m}$ apart for a total length of $50 \mathrm{~m}$. Auxiliary piers $1 \mathrm{~m}$ apart, also bearing microscopes, are placed between the $20-\mathrm{m}$ and the $25-\mathrm{m}$ piers. These provide intervals so that the $5-\mathrm{m}$ bar can be standardized by means of a calibrated 1-m bar. By use of a special bracket at the 15-m pier, a double pier at the $30-\mathrm{m}$ location, and an additional pier near the $45-\mathrm{m}$ pier, it is possible to mount microscopes at the 50-, 100-, and 150-ft points. In figure 4 are shown the $15-\mathrm{m}$ and $50-\mathrm{ft}$ microscopes at the extreme left, then the covered trough and carriages for the 5-m bar, immediately beyond that the six piers with their microscopes spaced $1-\mathrm{m}$ apart, and other piers beyond them.

In addition to the basic equipment of this comparator, there is the necessary auxiliary equipment, such as tape clamps, thermometers, etc.

Most of the work done with this comparator is with the $50-\mathrm{m}$ interval, and the use of this interval will be assumed for the remainder of this section. After the $50-\mathrm{m}$ interval is established by moving the 5-m bar to measure the distance between each of the 10 possible $5-\mathrm{m}$ intervals between microscopes, and the positions of the $0-$ and $50-\mathrm{m}$ points are transferred from the focuses of the microscopes to centers of two hemispheres in piers at floor level, the $5-\mathrm{m}$ bar is moved outside the $50-\mathrm{m}$ interval. An invar tape to be calibrated is then mounted in the comparator, supported on ballbearing wheels, and proper tension is applied to the tape by means of a calibrated weight.

The difference between the interval on the tape and the established $50-\mathrm{m}$ interval is obtained by the micrometer microscopes.

\section{Calibration of Line Standards of Length}

The measurement of line standards of length undertaken by the Bureau is classified under the several headings that follow. A complete calibration of this type of length standard includes the determination of the length at a known temperature and also of the expansivity usually expressed by the average coefficient of linear thermal expansion over a small range of temperature that embraces the temperatures at which the standard is likely to be used. For most work with any standard except one of the highest grade it is sufficient to assume a coefficient of expansion derived from a knowledge of the composition of the materials of which it is made. If the standard is subdivided, a calibration of the subdivisions may also be necessary. The number of intervals that it is advisable to compare will depend on the character of the standard and on the use to which it is to be put. In many cases 
it is unnecessary to determine the correction for the subdivisions; a proportionate part of the errors for the total length may be assumed. Where it is necessary to measure a greater or less distance than the full length of the standard it is only necessary, in many cases, to test a few subdivisions; for example, any distance in even feet may be accurately measured with a 100-ft tape if the corrections are known for the entire length of the tape, for each $10-\mathrm{ft}$ subdivision, and for each foot of the first $10 \mathrm{ft}$.

It should be noted that while platinum-iridium may be the best material for fundamental length standards, other materials are better suited to the needs of manufacture and industry; for example, steel rules and tapes are better for determining the sizes of steel and iron machine parts and structural members, because changes in length with changes in temperature are practically the same in the steel rule or tape as in the steel or iron part being measured.

Metric standards should be graduated to be correct at either $0^{\circ}$ or $20^{\circ} \mathrm{C}$, the latter temperature being preferred for everyday use because it eliminates to a great extent the question of differences in expansion. In this country, standards in the customary units of yards, feet, and inches are made to be correct at $68^{\circ} \mathrm{F}\left(20^{\circ} \mathrm{C}\right)$.

Requests for calibrations to be made by the Bureau should state the use to which the results are to be applied and also the accuracy desired, in order that the tests may be adequate for the end in view, avoiding unnecessary labor and expense. Where the highest attainable accuracy is needed, it is sometimes advisable to have the standard verified immediately before and again immediately after the important measurements in order to guard against possible changes due to undetected injury or structural alteration.

\subsection{Reference Standards}

This class includes standards of the highest type suitable for reference standards for makers of precision apparatus and for use in the most exact scientific investigations. One of the best constructions is that conforming to the specifications adopted for the prototype meters by the International Committee on Weights and Measures; but less expensive constructions are sufficient for all but exceptional purposes. The bars should be of the $X$-shaped or of the $H$-shaped cross section with all rulings in the plane of the neutral axis. The graduations should be accurately perpendicular to the longitudinal axis of the standard and lines must be fine, with sharp, smooth edges, and ruled on plane surfaces that have been given a faultless mirror or dull polish, depending upon the type of illumination used.

The lines on the prototype meters are about $0.006 \mathrm{~mm}$ wide. Since the time of the construction of these meters there has been a very marked tendency toward narrower lines and the use of microscopes of higher magnification than those used in the latter part of the last century. But, whatever may be the width of the line, it is most important that the line be symmetrical, that is; that the bottom of the groove made by the tracing mechanism be symmetrical with the edges of the groove line. The portion of the graduations tc be used should be defined by two parallel longitudinal lines about $0.2 \mathrm{~mm}$ apart. A material should be used that does not oxidize or otherwise tarnish on exposure to air or moisture. The graduations must not be covered by varnish or other protective covering.

$A$ very useful alloy is one made of approximately 36 percent of nickel and 64 percent of iron, knowr as invar. Invar possesses a coefficient of expan. sion that is almost negligible at ordinary temperatures; in addition, it does not rust or tarnish readily on exposure to the atmosphere. It is important tc remember that most materials, alloys in particular. undergo slight changes in the course of time, espe cially if subjected to considerable changes of tem perature or to mechanical disturbances. Hence whenever the highest accuracy is desired, standards should occasionally be verified. Standards of pure nickel and 42 percent of nickel have been found to be sufficiently stable for use as standards where verifications of the length of such bars can be made at suitable intervals of time.

The owner of a length standard of the reference class is usually justified in having a calibration made by the Bureau.

\subsection{Working Standards}

This class includes standards suitable for all ordinary precision work and suitable for the needs of college laboratories, manufacturers of the better grades of scientific apparatus, State superintendents of weights and measures, and most scientific work. Either an $\mathrm{H}$-shaped cross section or a rectangular cross section with provision for supports at definite positions should be used. Short bars such as decimeter bars, may be of rectangular cross section with the graduations on the upper surfact and with the bars supported directly on a flat surface. The lines of the graduations should be sharp and less than $0.03 \mathrm{~mm}$ wide, and they should be ruled on a plane, well-polished surface that will not tarnish readily on exposure to the atmosphere. Nc varnish or other protective covering should be used If the metal of the bar tarnishes readily, the lines should be ruled on plugs or strips of nontarnishing metal. Some such means as a pair of paralle longitudinal lines about $0.2 \mathrm{~mm}$ apart should be provided for defining the portion of the graduations to be used, and to facilitate the alinement of the bar. The graduation lines should be accurately perpendicular to the longitudinal axis of the stand. ard. Standards of this class are compared with working standards of the Bureau and are certified to $0.001 \mathrm{~mm}$ if their quality justifies it. 

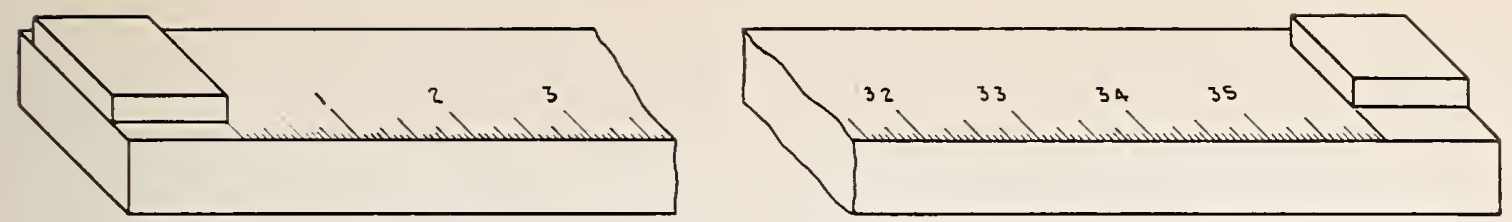

FIGURE 5. Line standard of length with contact pieces.

In the case of new working standards for State superintendents of weights and measures, it is recommended that these be graduated in millimeters for a distance of $1,010 \mathrm{~mm}$ or in $1 / 32$ in. for 37 in. In addition to the graduation, contact stops (fig. 5) are a convenience in some routine work, and a satisfactory arrangement is to have a contact extending across the standard at the zero line with a contact extending not overhalfway across at the yard or meter point, this latter contact being so placed as not to interfere with or cover any part of the graduations. The meter standard should be accurate to $0.01 \mathrm{~mm}$ or better at a temperature ${ }^{2}$ of $20^{\circ} \mathrm{C}$. The yard standard should be accurate to 0.0005 in. at $68^{\circ} \mathrm{F}$.

The owner of a working standard is sometimes justified in having a calibration made at the Bureau, but he may find that a calibration made by the maker or by himself is sufficient if a reference standard is arailable with which to make the comparison.

\subsection{Commercial Standards}

This class includes flat metal bars graduated along the center of the surface or along one or more edges, with lines less than $0.06 \mathrm{~mm}(0.0024$ in.) wide. They should be of sufficiently good grade to meet the requirements for drafting, machine work, etc., and to meet the needs of local sealers of weights and measures. It is recommended that those for the use of sealers be graduated in millimeters for a distance of 1,010 $\mathrm{mm}$ or in $1 / 32$ in. for $37 \mathrm{in}^{3}$ New meter standards should be accurate to $0.1 \mathrm{~mm}$ or better at a temperature of $20^{\circ} \mathrm{C}$, and new yard standards should be accurate to $0.005 \mathrm{in}$. at $68^{\circ} \mathrm{F}$.

Commercial standards seldom require calibration by the Bureau. Local sealers of weights and measures will usually have their standards calibrated by State officials, and most other users will be justified in relying upon the reputation of the manufacturers, especially if purchase specifications have prescribed the accuracy of the standards.

\section{Calibration of Measuring Tapes}

Steel and invar tapes used in surveying, engineering, manufacturing, and construction work are calibrated at the Bureau. Tapes intended for geodetic base-line work require a very accurate

Some bars have been made which were accurate at $0^{\circ} \mathrm{C}$, and these will

also be considered as meeting the requirements.
a Contact stops as described for working standards may also be used on sommercial standards for use by local sealers of weights and measures. calibration; steel tapes used for more routine work can be calibrated to sufficient accuracy, using simpler apparatus and procedures.

For the most accurate work, such as primary triangulation or extensive surveys, tapes of the alloy of nickel and steel, known as invar, when properly made, have been found to be the most satisfactory because of their low coefficient of expansion and the slowness with which they tarnish from exposure to the atmosphere. However, they require very careful handling in the field to prerent twists and kinks. Standardization before and after field measurements of first-order bases for triangulation is usually desirable. The width of the graduations should be uniform and not more than $0.04 \mathrm{~mm}$. The graduations should extend to one edge of the tape but not to the other, and all measurements should be made at the graduated edge.

Steel tapes have also been used for precise geodetic work, but require many precautions in their use to aroid errors caused by uncertainties as to the temperature of the tape. The coefficient of thermal expansion of both invar and steel tapes should be determined when they are used for work of the highest precision.

Ordinary 100-ft steel tapes to be used for engineering or construction work where an accuracy not better than $0.001 \mathrm{ft}$ is required may consist of a steel ribbon with the graduations directly on the tape, or the intervals may be indicated by groores or notches cut in sleeves securely fastened to the tape. Tapes having the intervals marked br rivets are not suitable for accurate work. Tapes having the zero mark at the edge of a ring and those having the terminal mark on a tension handle are not recommended for accurate work.

Tapes are compared with the steel-tape bench at the Bureau when supported throughout their entire length or when supported at specified points. These comparisons are accurate to the nearest $0.001 \mathrm{ft}$ or $0.2 \mathrm{~mm}$. When an accuracy greater than this is necessary, the Bureau is prepared to compare tapes of suitable length on its geodetic-tape comparator.

The standardization of a tape includes the comparison of the total length and of specially designated intervals. For most work it is sufficient to determine the total length only, and unless specifically requested to rerify intermediate intervals, the Bureau calibrates the total length only. If, however, it is desired to have a tape for measuring accurately any integral number of feet, it is usualiy sufficient to have measurements 
at every 10-ft point and at each foot of the first or of the last $10 \mathrm{ft}$.

As a basis for issuing a certificate and for placing its seal on a steel tape the Bureau has adopted the following specification and procedure.

\subsection{Specification for Standard Steel Tapes}

A steel tape is considered as standard when it has been calibrated by the Bureau and found to conform to the following specification: It shall be made of a single piece of metal ribbon, and none of the graduations shail be on pieces of solder or on sleeves attached to the tape or wire loops, spring balances, tension handles, or other attachments liable to be detached or changed in shape. The error in the total length of the tape, when supported horizontally throughout its length at the standard temperature of $68^{\circ} \mathrm{F}\left(20^{\circ} \mathrm{C}\right)$ and at standard tension, shall not be more than 0.1 in. per $100 \mathrm{ft}(2 \mathrm{~mm}$ per $25 \mathrm{~m})$. The standard tension is $10 \mathrm{lb}(4.5 \mathrm{~kg})$ for tapes 25 to $100 \mathrm{ft}$ or from 10 to $30 \mathrm{~m}$ in length and $20 \mathrm{lb}(9 \mathrm{~kg})$ for tapes longer than $100 \mathrm{ft}$ or $30 \mathrm{~m}$.

\subsection{Certification of Tapes}

Tapes conforming to the specification will be certified by the Bureau and a precision seal showing year of standardization will be placed on each tape so certified. For tapes not conforming to the specification, a report will be issued, but the tapes will not be sealed. The Bureau's serial number on a tape simply signifies that it has been tested by the Bureau and either a certificate or a report issued.

Ordinarily the length of a steel tape is certified or reported by the Bureau to the nearest $0.001 \mathrm{ft}$ or $0.0002 \mathrm{~m}(0.2 \mathrm{~mm})$.

The specification given in section 6.1 is intended to cover steel tapes of highest precision and should not be taken to imply that only tapes conforming to it are suitable for use. For instance, tapes having a terminal graduation at the end of a ring are very desirable for certain purposes, where convenience is of more importance than high accuracy, and the Bureau will make the necessary observations and report on such tapes if satisfactory in other respects.

\subsection{Standard Procedures in Steel-Tape Calibrations}

Unless otherwise stated, the comparisons of the tape with the bench standard are made at the center of the lines on the edge to which the shortest graduations are ruled. If all the graduations extend entirely across the tape, the ends farthest from the observer when the zero of the tape is at his left hand are used. On tapes that have been cut off at the zero mark, the extreme end of the steel ribbon is taken as the zero point and not the center of any line that may be at that point. On tapes that have the zero point on a loop attached to the steel ribbon at the end, the zero is taken at the outside of this loop, unless noted to the contrary.

Measurements for the calibration of a tape at the Bureau are made only at points at which the tape is supported.

The standard tension given in the specification is for a tape when supported on a horizontal flat surface. No standard tension has been officially adopted for a tape when supported in any other manner. The Bureau is sometimes requested to calibrate a tape supported throughout and supported at ends only under "standard tension." In such cases the Bureau uses the same tension for the tape supported at the ends as is used as standard tension when supported throughout. Many surveyors and engineers use a tension somewhat greater than this standard tension when they are using a tape supported at the ends only. The correction for sag for a given tension increases directly as the square of the increase of the weight per unit length of the tape. In the case of very heavy tapes the standard tensions of 10 and 20 lb (4.5 and $9 \mathrm{~kg})$ may be found to be inadequate for tapes supported at the ends only. It is suggested that, dependent on the length of the tape and its weight per unit length, tensions in the range of 20 to $40 \mathrm{lb}$ (9 to $18 \mathrm{~kg}$ ) be used for tapes used in single catenary type of suspension. Tapes weighing $0.018 \mathrm{lb} / \mathrm{ft}$ or more may be considered as heavy tapes. Tapes weighing 0.009 to 0.011 $\mathrm{lb} / \mathrm{ft}$ may be considered as light tapes.

In the standardization of invar tapes the following tensions are used, unless otherwise specified: $20 \mathrm{lb}$ for $50-, 100-$, and $150-\mathrm{ft}$ tapes, and $15 \mathrm{~kg}$ for $30-$ and $50-m$ tapes.

When the lengths of intervals are desired on a tape supported at points that are more than 200 $\mathrm{ft}$ or $50 \mathrm{~m}$ apart, these lengths must be computed from quantities directly observed, using the mathematical expression for the sag as given in the appendix.

Since the present tape testing laboratory has been in use the observations have usually been made at a temperature very close to $68^{\circ} \mathrm{F}\left(20^{\circ} \mathrm{C}\right)$. Occasionally this may not be possible. The coefficient of expansion of the bench standard has been determined, and the difference between this value and the coefficient of expansion of steel tapes is taken into account whenever necessary. $A$ value for the coefficient of expansion of 0.00000645 per deg F $(0.0000116$ per deg C) is assumed for steel tapes. This coefficient may be considered as correct for all except the most precise geodetic tapes. Determinations of the coefficients of expansion of both ordinary steel tapes and stainless-steel tapes give the value stated above within the limits of all ordinary measurements ever made with these tapes. The Bureau determines the coefficient of expansion of steel tapes only when sufficient need for such a determination is clearly indicated and when the value of the coefficient usually assumed for steel tapes may lead to difficulty. 
Tapes made by the manufacturers that supply the surveying and engineering trade with highgrade steel tapes are almost universally correct for total length at standard tension and temperature within $0.01 \mathrm{ft}$, and ordinarily within $0.006 \mathrm{ft}$. Hence, for most work not requiring an accuracy better than $0.01 \mathrm{ft}$, where a certified tape is not required by law or by the terms of a contract, it is not necessary to submit the tape to the Bureau for a calibration. As high-grade tapes are ordinarily uniformly graduated within a few thousandths of a foot, the calibration of subintervals of a tape is not required except when rather precise measurements are to be made with the tape, that is, measurements to a few thousandths of a foot. The owner of a tape can often check the uniformity of division of the tape by measuring, for example, a $25-\mathrm{ft}$ distance by using the intervals from 0 to $25 \mathrm{ft}, 25$ to $50 \mathrm{ft}, 50$ to $75 \mathrm{ft}$, and 75 to $100 \mathrm{ft}$ on the tape.

\subsection{Corrections Applicable to Steel Tapes}

Then a tape has been calibrated under one set of conditions and it is desired to use it under another set of conditions, it is often possible to calculate with sufficient accuracy the difference in the length of the tape under the two conditions. Information on this subject useful to surveyors has been included in the appendix.

\subsection{Base-Line Tapes}

When an invar base-line tape is submitted the first time for calibration on the geodetic comparator, the normal procedure is to determine its coefficient of thermal expansion and its weight per unit length before undertaking the standardization of its length. At one time it was thought necessary to check the stability of invar tapes by "whipping" them rhythmically and determining the changes in length caused by each group of whippings. Tapes received in recent years have been found to be sufficiently stable, and the whipping test has been discontinued. For the determination of its coefficient of expansion the electrical-resistance method described by Peter Hidnert and Richard K. Kirby ${ }^{4}$ is used.

Calibrations are usually made on the geodetic comparator under conditions similar to those used in the field. The standard calibrations now made for the U. S. Coast and Geodetic Survey on their base-line tapes are those to determine the length at $25^{\circ} \mathrm{C}$ of the interval 0 to $50 \mathrm{~m}$ with the tape under a horizontal tension of $15 \mathrm{~kg}$ when supported at the $0-, 25-$, and $50-\mathrm{m}$ points, and then when supported at the $0-, 12.5-, 37.5-$, and $50-\mathrm{m}$ points, with the 12.5 - and $37.5-\mathrm{m}$ points 6 in. above the place of the 0 - and $50-\mathrm{m}$ supports. This second condition of supports is to duplicate conditions used in the field when surveying along railroad

4. P. Hidnert and R. K. Kirby, A new method for determining linear thermal expansion of invar geodetic surveying tapes, J. Research NBS 30, 179 (1953) RP2407. rails. For these field conditions the tapes are suppcrted at the 12.5- and $37.5-\mathrm{m}$ points on rollers, with the tops 6 in. above the rails. The height of 6 in. was chosen because all invar tapes possessed by the U. S. Coast and Geodetic Survey would then be lifted off the rail at the $25-\mathrm{m}$ point. All measurements are made in the laboratory and in the field with thermometers weighing $45 \mathrm{~g}$ each attached at points $1 \mathrm{~m}$ inside the terminal graduations. For first-order work the values for the lengths of the intervals are certified not to be in error by more than 1 part in 500,000. Although all measurements are made on a new tape with the same care and just as accurately as in subsequent calibrations, the Bureau has made it a practice not to certify any base-line tape to first-order accuracy until further calibrations indicate that it is a stable tape so that first-order accuracy has a meaning. The terms "first-order" and "second-order" are those adopted in geodetic field surveying. Tapes certified to second-order accuracy have a certified accuracy of 1 part in 250,000 .

When base-line tapes are submitted to the Bureau rather frequently it is recommended that, in calibrations after the initial, and one or more subsequent standardizations, the work be abbreviated. Measurements sufficient to show that values of the length have not changed more than the limit of error claimed in the previous calibration are made more easily than those required for a new certification. A statement that the previous certificate may continue to be used is issued when the abbreviated test shows that the values in the previous certificates are still valid.

If thermometers having a weight other than $45 \mathrm{~g}$ are used with base-line tapes in the field, that fact should be stated when the tapes are submitted for calibration. The thermometers may be submitted so that they can be placed at the proper positions on the tapes during the calibration.

\section{Certificates and Reports}

If apparatus submitted for calibration fulfills the requirements for certification, a certificate is issued. Values given in certificates or reports are applicable at the time of the calibration; there is no guarantee of the continued applicability of these values.

A National Bureau of Standards serial identification number similar to that shown below

\section{NBS No. 2147}

is usually engraved, stamped, or etched on apparatus, tapes, and standards that have been calibrated by the Bureau and for which a certificate or report has been issued. An identification number is not ordinarily placed on any precise standard when there is any danger of possible injury or of minute changes of length being caused, nor in certain other cases where there is already adequate identification. 
Tapes and other articles for which definite tolerances have been prescribed are marked with a seal by the Bureau if the article is found to conform to the specifications. If a certificate or report is issued for such an article, a serial identification number, referred to above, is also placed on the article in addition to the seal.

\section{Cooperation with Officials and Others}

The Bureau will be pleased to assist investigators, manufacturers, and others by furnishing any information at its disposal concerning methods of measurement. It is also the desire of the Bureau to cooperate with manufacturers, scientists, weights and measures officials, and others in bringing about more satisfactory conditions relating to standards, physical constants, measuring instruments, and methods involved in length measurements. It is always desirous of receiving samples or descriptions of new apparatus or improvements on any type of apparatus mentioned in this Circular. Persons interested are invited to visit the laboratories of the Bureau, examine the apparatus and methods, and confer with those in charge regarding any problems they may have.

\section{General Instructions to Applicants for Calibrations}

\subsection{Apparatus Accepted for Calibration}

The Bureau will accept for calibration only a standard or an apparatus that is well made and not likely to change excessively. An adequate degree of quality is insisted upon as a prerequisite to acceptance for calibration. Line standards of length should be made of suitable material, such as iron alloy, brass, bronze, platinum alloy, or glass, and should be of a construction and workmanship suitable for the intended accuracy. Poorly divided scales on metal, and scales graduated on wood, plastics, or paper will not be accepted. In general, a linear scale of a grade better than the best machinist's scales will be required for a calibration by the Bureau.

\subsection{Application for Calibration}

All articles submitted for calibration should be accompanied by a written request. This request should enumerate the articles, giving the identification marks of each, and should state explicitly the nature of the calibration desired and an approximate valuation of the articles should be stated for use in insuring the return shipment.

\subsection{Nature of Calibration}

The application should state clearly the nature of the calibration desired, namely, the points at which measurements are to be made and the temperature, especially if other than standard, or any other conditions. The most accurate results can be obtained and delays are avoided only when such full information is given. It is also desirable that the Bureau be informed as to the conditions under which the apparatus is used and the character of the work for which it is employed.

\subsection{Special Calibrations}

The Bureau will gladly cooperate with scientific investigators, manufacturers of apparatus, and others who need ligher precision than is provided in the regular schedules by undertaking special calibrations as far as the regular work of the Bureau will permit. Kinds of calibrations not at present provided for may be undertaken if the work is important and the facilities and time are available. Approved calibrations not provided for in the regular schedules are considered special, and a special fee is charged for them. These should be arranged for by correspondence before shipment of the apparatus. The application should state fully the purpose for which the apparatus has been used or is to be used in the future, the need for the calibration, and the precision desired. The special fee charged depends chiefly upon the time consumed and the amount of alteration required in the Bureau's regular calibrating apparatus. It is ordinarily possible to give an estimate of the fee when so requested.

\subsection{Condition of Apparatus}

Before submitting apparatus for calibration, the applicant should ascertain that it fully satisfies the requirements for the calibration desired. It must be in good working condition. No repair work is done at the Bureau. If repairs are needed, either they should be made by the applicant, or the item should be sent to the maker before it is submitted for calibration. When defects, found after observations have been begun, exclude any apparatus from receiving the usual certificate, a report is rendered giving such information as has been found. In such cases a fee is charged, depending upon the time consumed. All possible care is taken in handling apparatus, but the risk of injury or breakage in shipment or at the Bureau must be borne by the applicant.

\subsection{Identification of Apparatus}

All packages should be plainly marked with the shipper's name and address and should contain a list of the contents. Each separate piece of apparatus or sample of material should be provided with an identification mark or number. The identification mark should be given in the application.

\subsection{Shipping Instructions}

Apparatus should be securely packed in cases or packages that will not be broken in transportation and that may be used in returning them to the 
owner. The shipment in both directions is at the applicant's risk. Great care should be taken in packing. Clean, dry excelsior is a suitable packing material in most cases. Metal parts should be well protected from corrosion by oil or grease. Each instrument should also be wrapped in strong, waxed paper or other suitable covering to exclude dust and excelsior. The tops of boxes should be put on with screws, as any shock due to nailing and the subsequent opening is likely to cause damage. The tops of the shipping boxes should have the return or forwarding address on the underside. Transportation charges are payable by the party making the request. The charges for shipment to the Bureau must be prepaid, and, unless othermise arranged, articles are usually returned or forwarded br express "collect." Information regarding the disposition of apparatus after completion of the measurements, including a statement as to the address to which shipment should be made and as to choice of carrier, should be supplied. In case such information is not given, it is understood that the calibrated apparatus is to be returned to the shipper.

\subsection{Schedules of Test Fees}

Schedules of test fees for the calibration of line standards of length and for steel tapes and invar base-line tapes have been established. Copies of these schedules may be obtained on application.

\subsection{Address}

Apparatus submitted for calibrations described in this Circular, as well as correspondence relating thereto, should be addressed: National Bureau of Standards, Washington 25, D. C., Attention: Dirision 2.4

The author expresses lis appreciation to B. L. Page, R. F. Ackermann, and J. S. Beers for their suggestions during the final rerision of the manuscript.

\section{Appendix-Use of Steel Tapes}

In the use of steel tapes for precision work, attention should be paid to the temperature of the tape and to the tension applied to the tape. Corrections are sometimes necessary to take account of variations between the conditions of field measurement from those of the laboratory calibration as shown in the certificate or report. The accuracy of the balance or tension handle employed for applying tension should be checked by comparison with a calibrated balance or by the use of calibrated weights used with a pulley wheel so that the balance is being calibrated in a horizontal position.

Young's Modulus of Elasticity. A value for Young's modulus of elasticity is sometimes required in computing the length of a tape as used in the field under conditions differing from those used in the calibration laboratory.

In a series of measurements made several years ago at the National Bureau of Standards on a group of 45 steel tapes, the value for Young's modulus of elasticity was determined to be $28.0 \times 10^{6}$ (that is $\left.28,000,000\right) \mathrm{lb} / \mathrm{in}^{2}$.

Variations in the material in the different tapes cause an uncertainty of 0.2 or $0.3 \times 10^{6}(200,000$ or 300,000$) \mathrm{lb} / \mathrm{in}^{2}$.

A tape having the customary black finish has a smaller modulus of elasticity than has the original steel ribbon from which it is made, because there is included in the cross-sectional area of the finished tape not only the steel but also the protective coating which has a lower modulus. A value of $28.0 \times 10^{6} \mathrm{lb} / \mathrm{in}^{2}$. may for all practical purposes be assumed for any steel tape, because the maximum error introduced by this assumption in using a $200-\mathrm{ft}$ tape with a change in tension of $15 \mathrm{lb}$ would be about $0.001 \mathrm{ft}$.

Correction for Sag. ${ }^{5}$ The difference in the length of a tape when supported throughout and when supported at equidistant points at the same height, the tension remaining constant, is equal to

$$
\frac{L}{24}\left(\frac{w d}{P}\right)^{2},
$$

where $L$ is the length of the tape, $w$ is the weight of the tape per unit length, $d$ the distance between points of support, and $P$ the tension on the tape. These must be in consistent units; usually $L$ and $d$ in feet, $w$ in pounds per foot and $P$ in pounds.

In a study of a group of 45 tapes, previously mentioned $\mathrm{t}$ was found that, using tensions between 10 and $25 \mathrm{lb}$, the difference between the observed value and that obtained from the formula for the correction for sag did not exceed $0.001 \mathrm{ft}$ when the interval between the supports was 25 or $50 \mathrm{ft}$. Furthermore, when supported at the 0 and 100-ft points at $10 \mathrm{lb}$ tension, the difference between the observed value and the computed value for the correction for sag did not exceed $0.002 \mathrm{ft}$, provided the correction for sag was not larger than $0.060 \mathrm{ft}$. When the tension was increased to 15,20 , or $25 \mathrm{lb}$, under the same conditions of support, the difference between the observed values and the computed value for the correction for sag, with the exception of a few tapes, did not exceed $0.001 \mathrm{ft}$. Moreover, there may be an agreement between the observed value and the computed value to $0.001 \mathrm{ft}$ for individual tapes of relatively heavy weight when under a tension less than $15 \mathrm{lb}$. The formula was shown to be applicable to $100-\mathrm{ft}$ tapes of nonuniform density, provided sufficient tension was used, e. g., $15 \mathrm{lb}$ or more.

As an example of the use of the formula expressing the correction for sag one may consider a tape weighing $0.0080 \mathrm{lb}$ per linear foot that has a length of $200.004 \mathrm{ft}$ when supported horizontally throughout at a tension of 20 $\mathrm{lb}$ and that is to be used supported at the 0 - and $200-\mathrm{ft}$ points at that tension. The length may be readily computed to be

$200.004-\frac{200}{24}\left(\frac{0.0080 \times 200}{20}\right)^{2}=200.004-0.053=199.951 \mathrm{ft}$.

It will be noted that nominal values for $L$ and $d$ are used. If the tape is to be used at a tension of $25 \mathrm{lb}$, then the length of the tape supported throughout at $25 \mathrm{lb}$ should be determined.

Tension of Accuracy. If the length of a tape is known when supported throughout its length at standard tension and standard temperature, this information, together with a knowledge of certain constants concerning the physical properties of the tapes will enable one to determine the tension (tension of accuracy) to apply to the tape when supported at equidistant points at any known temperature to obtain the nominal length. These constants should be accurately determined. The case in which the observed temperature is the same as the standard temperature is given in text books on serveying, and the tension to be used in this case is often termed the normal tension. It is found by equating the correction for tension to the cor-

5 Lewis V.Judson, Effect of concentrated loads on the length of measuring tapes, BS Sci. Pap. 21, 390 (1926) S534. 


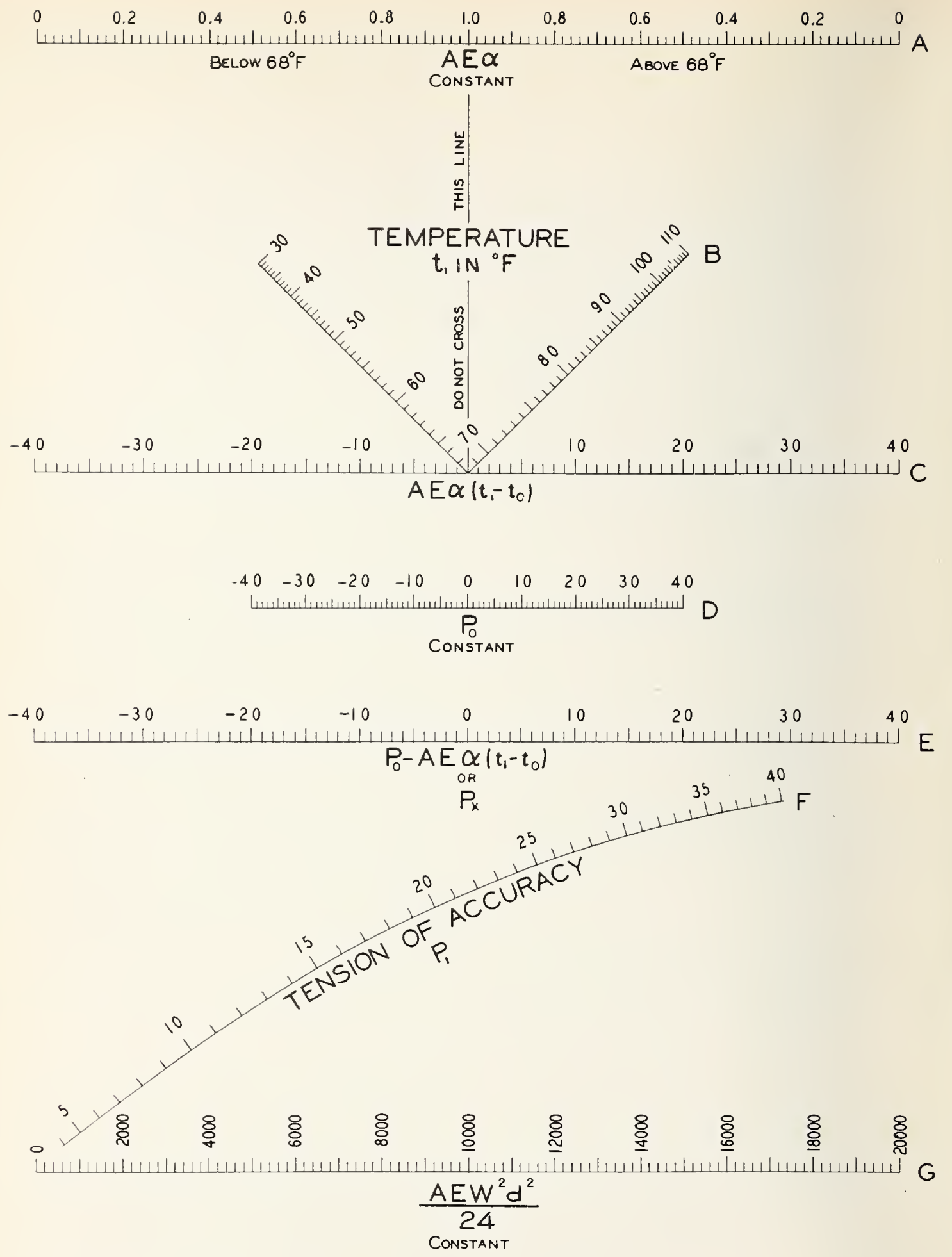

Figure 6. Nomogram for steel tapes. 
rection for sag. The general case is an extension of this specified case. The equation is

$$
P_{1}^{3}-\left[P_{0}-A E \alpha\left(t_{1}-t_{0}\right)\right] P_{1}^{2}-\frac{A E w^{2} d^{2}}{24}=0,
$$

where $P_{1}=$ Tension to be applied to the tape, when used at the observed temperature, $t_{1}$, and supported at equidistant points at a distance, $d$, apart, in order that the tape will have its nominal length.

$P_{0}=$ Tension at which tape has its nominal length when supported throughout at standard temperature, $t_{0}$.

$A=$ Cross-sectional area of the tape.

$E=$ Young's modulus of elasticity.

$\alpha=$ Coefficient of thermal expansion.

$t_{1}=$ Observed temperature.

$t_{0}=$ Standard temperature.

$w=$ Weight of the tape per unit length.

$d=$ Distance between the equidistant points of support.

As it is difficult to determine $A$ directly with sufficient accuracy, it is usually advisable to determine the product $A E$, which is equal to $\left(P_{2}-P_{1}\right) L / \Delta L$, where $L$ is the nominal length of the tape supported throughout, and $\Delta L$ is the change in length when the tension is changed from $P_{1}$ to $P_{2}$.

Nomogram for Tension of Accuracy. The solution of the cubic equation to determine the tension of accuracy of a tape supported in a catenary can be carried out rapidly by graphical means, using a nomographic chart, the equation being in Soreau's ${ }^{8}$ canonical form $I V_{0}$.

Figure 6 is such a chart, the value of $\alpha$ being 0.00000645 per deg $\mathrm{F}$, and $t_{0}$ is $68^{\circ} \mathrm{F}$. To use this chart to find the tension of accuracy, $P_{1}$, for a tape, place a straightedge on the point representing the constant $A E \alpha$, axis $\mathrm{A}$, and on the point representing the observed temperature $t_{i}$, inclined scale $\mathrm{B}$. The intersection of the straightedge with the dummy axis $\mathrm{C}$ is noted. The straightedge is then placed on this point and on the point representing the value $P_{0}$, axis $\mathrm{D}$. The point where the straightedge intersects axis $\mathrm{E}$ is determined. Place the straightedge

'Soreau, Nomographie, pages 172, 174, 184, and 192 (Chiron, Paris, 1921). on this point and the point representing the constant $\left(A E w^{\varepsilon} d^{2}\right) / 24$, axis $\mathrm{G}$. The point where the straightedge intersects curve $\mathrm{F}$ determines the tension to apply to the tape under the given method of support and at the observed temperature $t_{1}$.

It should be noted that the constants $A E \alpha, P_{0}$, and $\left(A E w^{2} d^{2}\right) / 24$ are constants of the tape, independent of the conditions of its use and can be permanently marked on the chart for each tape, in the office, in preparation for use of the chart in the field.

It should be noted that for short lengths of tapes the value of the constant $K=\left(A E w^{2} d^{2}\right) / 24$ will be small. The point of intersection of the straightedge with axis $F$ will then often be somewhat indefinite on the chart, although the calculated value of the intersection is of course definite. This, however, is not serious as the length of a short interval of a tape changes very little for a 1 or $2 \mathrm{lb}$ ehange in tension. For example, a 25 -ft length of tape weighing $0.010 \mathrm{lb} / \mathrm{ft}$ will change in length only approximately 0.002 in. when the tension is changed from 10 to $12 \mathrm{lb}$ when supported at the 0 and 25 -ft intervals.

For $100-\mathrm{ft}$ tapes, using the $100-\mathrm{ft}$ interval, the change in length is very apparent for a 0.5 -lb change in tension. In this case the chart and formula liave been found to be in agreement with the observed values determined by actual test for various tapes tested at the Bureau. Although fewer tests have been made for tapes longer than $100 \mathrm{ft}$, it is believed that the chart and formula will apply equally as well.

Other nomograms may be drawn whose constants do not come within the scales on the nomogram shown in figure 6 , of if conditions are such that a greater accuracy can be used than can be obtained on this chart, a new one can be drawn on suitable paper, with axes $\mathrm{E}$ and $\mathrm{G}$ further apart.

Attention is also called to the fact that the value $P_{0}$ determined for the total length or for one specified interval of a tape does not necessarily apply to all intervals on the tape. This may be due to one or more of the following conditions: A slight nonuniformity of graduation, a lack of homogeneity, or a lack of uniformity in cross section of the tape. For example, for one tape weighing $0.010 \mathrm{lb} / \mathrm{ft}$, the value $P_{0}$ was found to vary from 0.5 to $1 \mathrm{lb}$ for the intervals 0 to $25 \mathrm{ft} 0$ to $50 \mathrm{ft}, 0$ to $75 \mathrm{ft}$, and 0 to $100 \mathrm{ft}$.

Washington, D.C., February 16, 1960 


\section{SELECTED WEIGHTS AND MEASURES PUBLICATIONS OF THE \\ NATIONAL BUREAU OF STANDARDS}

NBS Handbook 44 2d Edition-1955 Specifications, Tolerances, and Regulations for Commercial Weighing and Measuring Devices. Loose Leaf (does not

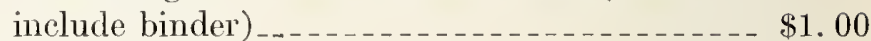

NBS HaNDBook 45 Testing of Measuring Equipment

NBS Handвoок 67 Checking Prepackaged Commodities____._.__ . 35

NBS Circular 501 Federal and State Weights and Measures Laws_ _ $\quad 6.50$

NBS Circular 540 Weights and Measures Case Reference Book_-_ 1.25

NBS Circular 547 Precision Laboratory Standards of Mass and

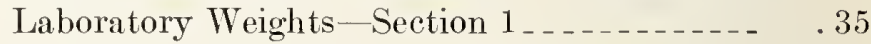

NBS Circular 593 The Federal Basis for Weights and Measures_-_- . 30

\section{AVAILABLE REPORTS OF THE}

\section{NATIONAL CONFERENCE ON WEIGHTS AND MEASURES}

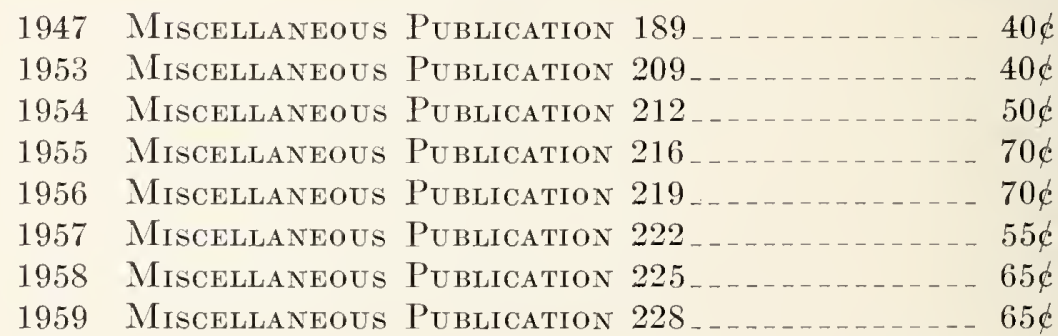

Index to the Reports of the National Conference on Weights and Measures from the First to the Thirty-sixth, 1905 to 1951, Miscellaneous Publication 203_............. 20 c

ORDER ALL PUBLICATIONS, WITH REMITTANCE, FROM TIE SUPERINTENDENT OF DOCUMENTS, GOVERNMENT PRINTING OFFICE, WASHINGTON 25, D.C. 


\section{THE NATIONAL BUREAU OF STANDARDS}

'The scope of activities of the National Bureau of Standards at its major laboratories in Washington, D.C., and Boulder, Colorado, is suggested in the following listing of the divisions and sections engaged in technical work. In general, each section carries out specialized research, development, and engineering in the field indicated by its title. A brief description of the activities, and of the resultant publications, appears on the inside of the front cover.

WASHINGTON, D.C.

Electricity and Electronics. Resistance and Reactance. Electron Devices. Electrical Instruments. Magnetic Measurement. Dielectrics. Engineering Electronics. Electronic Instrumentation. Electrochemistry.

Optics and Metrology. Photometry and colorimetry. Optical Instruments. Photographic Technology. Length. Engineering Metrology.

Heat. Temperature Physics. Thermodynamics. Cryogenic Physics. Rheology. Molecular Kinetics. Free Radicals Research.

Atomic Physics. Spectroscopy. Radiometry. Mass Spectrometry. Solid State Physics. Electron Physics. Atomjc Physics.

Radiation Physics. Neutron Physics. Radiation Theory. Radioactivity. X-ray. High Energy Radiation. Nucleonic Instrumentation. Radiological Equipment.

Chemistry. Organic Coatings. Surface Chemistry. Organic Chemistry. Analytical Chemistry. Inorganic Chemistry. Electrodeposition. Molecular Structure and Properties of Gases. Physical Chemistry. Thermochemistry. Spectrochemistry. Pure Substances.

Mechanics. Sound. Mechanical Instruments. Fluid Mechanics. Engineering Mechanics. Mass and Scale. Capacity, Density, and Fluid Meters. Combustion Controls.

Organic and Fibrous Materials. Rubber. Textiles. Paper. Leather. Testing and Specifications. Polymer Structure. Plastics. Dental Research.

Metallurgy. Thermal Metallurgy. Chemical Metallurgy. Mechanical Metallurgy. Corrosion. Metal Physcis.

Mineral Products. Engineering Ceramics. Glass. Refractories. Enameled Metals. Constitution and Microstructure.

Building Technology. Structural Engineering. Fire Protection. Air Conditioning, Heating, and Refrigeration. Floor, Roof, and Wall Coverings. Codes and Safety Standards. Heat Transfer. Concreting Materials.

Applied Mathematics. Numerical Analysis. Computation. Statistical Engineering. Mathematical Physics.

Data Processing Systems. SEAC Engineering Group. Components and Techniques. Digital Circuitry. Digital Systems. Analog Systems. Applications Engineering.

- Office of Basic Instrumentation.

- Office of Weights and Measures.

\section{BOULDER, COLORADO}

Cryogenic Engineering. Cryogenic Equipment. Cryogenic Processes. Properties of Materials. Gas Liquefaction.

Radio Propagation Physics. Upper Atmosphere Research. Ionosphere Research. Regular Prediction Services. Sun-Earth Relationships. VHF Research. Radio Warning Services. Airglow and Aurora. Radio Astronomy and Arctic Propagation.

Radio Propagation Engineering. Data Reduction Instrumentation. Radio Noise. Tropospheric Measurements. Tropospheric Analysis. Propagation-Terrain Effects. Radio-Meteorology. Lower Atmospheric Physics.

Radio Standards. High-Frequency Electrical Standards. Radio Broadcast Service. Radio and Microwave Materials. Atomic Frequency and Time Standards. Electronic Calibration Center. Microwave Circuit Standards.

Radio Communication and Systems. Low Frequency and Very Low Frequency Research. High Frequency and Very High Frequency Research. Modulation Systems. Antenna Research. Navigation Systems. Systems Analysis. Field Operations. 
